\title{
The Biology of a Prostate Cancer Metastasis Suppressor Protein: Raf Kinase Inhibitor Protein
}

\author{
Evan T. Keller,* Zheng Fu, and Meghan Brennan \\ Department of Urology, University of Michigan, Ann Arbor, Michigan
}

\begin{abstract}
Raf kinase inhibitor protein (RKIP) was originally identified as a protein that bound membrane phospholipids and was named phosphatidylethanolamine binding protein-2 (PEBP-2). RKIP was than identified as a protein that bound Raf and blocked its ability to phosphorylate MEK, thus earning its new name of RKIP. Subsequent to identification of its role in the Raf:MEK pathway, RKIP has been demonstrated to regulate several other signaling pathways including G-protein signaling and NF-KB signaling. Its involvement in several signaling pathways has engendered RKIP to contribute to several physiological processes including membrane biosynthesis, spermatogenesis, neural development, and apoptosis. RKIP is expressed in many tissues including brain, lung, and liver and thus, dysregulation of RKIP expression or function has potential to contribute to pathophysiology in these tissues. Loss of RKIP expression in prostate cancer cells confers a metastatic phenotype on them. Additionally, restoration of RKIP expression in a metastatic prostate cancer cell line does not effect primary tumor growth, but it does inhibit prostate cancer metastasis. These parameters identify RKIP as a metastasis suppressor gene. In this review, the biology and pathophysiology of RKIP is described. J. Cell. Biochem. 94: 273-278, 2005. (c) 2004 Wiley-Liss, Inc.
\end{abstract}

Key words: prostate carcinoma; metastasis; signal transduction; apoptosis; PEBP

Raf kinase inhibitor protein (RKIP) is a member of the phosphatidylethanolamine binding protein (PEBP) family. The RKIP family of proteins is highly conserved and does not share significant homology with other protein families [Banfield et al., 1998]. RKIP is a small, cytosolic protein originally purified from bovine brain and identified to bind phospholipids [Yeung et al., 1999; Vallee et al., 2001; Simister et al., 2002]. RKIP was initially identified as human PEBP where it was shown to have a role in lipid metabolism and phospholipid membrane biogenesis. Recent investigations have identified that RKIP inhibits Raf-mediated activation of MEK, which accounts for it current name. Aberrant RKIP activity is associated with an increasing number of diseases via its associa-

Grant sponsor: National Cancer Institute; Grant number: CA098513.

*Correspondence to: Evan T. Keller, DVM, PhD, Room 5304 CCGCB, 1500 E. Medical Center Dr., University of Michigan, Ann Arbor, MI 48109-0940.

E-mail: etkeller@umich.edu

Received 22 April 2004; Accepted 23 April 2004

DOI 10.1002/jcb.20169

(c) 2004 Wiley-Liss, Inc. tion with signal transduction pathways [Mitake et al., 1995, 1996; Banfield et al., 1998; Tsugu et al., 1998; Yeung et al., 1999; Maki et al., 2002; Simister et al., 2002; Corbit et al., 2003]. In this review, the biology and pathophysiology of RKIP is described.

\section{LOCALIZATION OF RKIP}

Immunohistochemical analysis of RKIP expression reveals that it is often found present in the cytoplasm and at the plasma membrane in many different tissues [Simister et al., 2002]. RKIP expression is found in a variety of neural cells including brain oligodendricytes, Schwann cells, Purkinje cells of the cerebellum, and within cortical and hippocampal layers of the brain [Katada et al., 1996, 2000; Moore et al., 1996; Taiji et al., 1996; Frayne et al., 1998, 1999]. In addition, RKIP is expressed in a large number of non-neural tissues including spermatids, Leydig cells, and epididymal epithelium of the testis; steroidogenic cells of the adrenal gland zona fasciculata; proximal kidney tubule epithelium; enterocytes, goblet cells, and plasma cells of the small intestine; plasma cells of the lymph node; plasma cells; and megakaryocytes of the spleen; heart; liver; and 
epididymis, lung bronchioles, mesenteric lymph node, oviduct, ovary, lactating mammary glands, uterus, prostate epithelium, and thyroid [Frayne et al., 1998; Fu et al., 2003]. Although it is found in many secretory organs, RKIP is not found extracellular fluids such as blood, saliva, milk, uterine fluid, parotid fluid, prostate secretions, or seminal vesicle secretions [Schoentgen and Jolles, 1995].

\section{RKIP FUNCTION}

The wide distribution of RKIP in many different tissues suggests that it plays a role in a multitude of different physiological processes (Fig. 1). In neural tissues, RKIP was found to enhance in vitro acetylcholine synthesis by upregulating choline acetyltransferase and possibly stimulating cholinergic neuronal pathways in rat medial septal nuclei [Mitake et al., 1995; Ojika et al., 1995; Taiji et al., 1996; Tohdoh et al., 1997].

RKIP also has several functions in gonadal tissues. For example, rat epididymal secretions and sperm plasma membranes contain proteins with sequences similar to bovine brain RKIP [Jones and Hall, 1991]. Furthermore, RKIP released from spermatozoa may be involved with membrane biogenesis and maintenance of antigen segregation in spermatozoa [Perry et al., 1994]. Studies in the rat testis show that RKIP proteins may be involved in organization of the seminiferous epithelium or the transfer of phosphatidylethanolamine to other germ cells [Saunders et al., 1995]. Due to its presence in

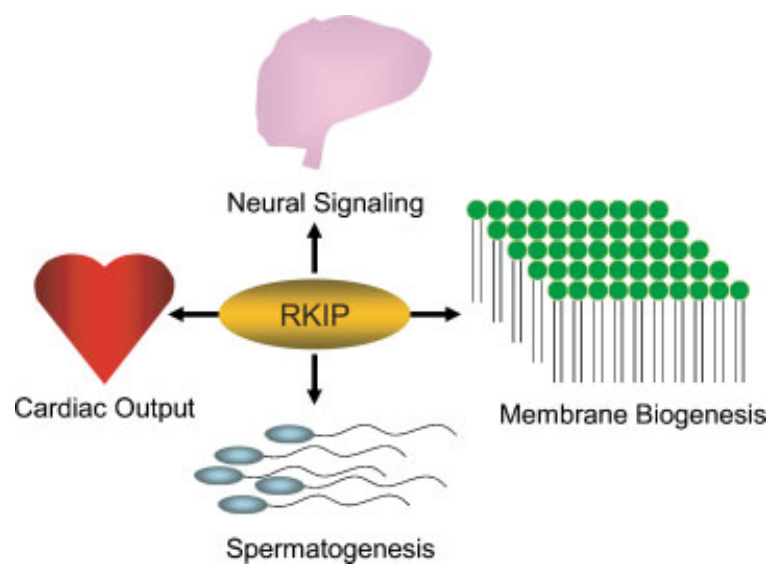

Fig. 1. Physiological roles of RKIP. RKIP has multiple functions in organs such as the heart and brain and at the cellular level as indicated. [Color figure can be viewed in the online issue, which is available at www.interscience.wiley.com.]
Leydig cells, Frayne et al. [1999] suggested a role for RKIP as a lipid carrier or binding protein within the rat testis that contributes to membrane organization during spermatogenesis.

\section{RKIP AND INTRACELLULAR SIGNALING}

RKIP modulates a variety of different signal pathways (Fig. 2). The role of RKIP in cell signaling was identified in a yeast two-hybrid assay for screening clones from a human T-cell library that bound to Raf-1 kinase binding domains [Yeung et al., 1999]. RKIP was shown to bind Raf-1, MEK-1, and weakly bind to ERK2, interfering with MEK phosphorylation and activation by Raf-1. However, RKIP was not a substrate for Raf-1 or MEK. RKIP did not bind to Ras, nor possess kinase activity. It appears that RKIP acts to set the threshold for Raf-1 activation and subsequent activation of the MEK/ERK pathway. Raf-1 dissociates from its complex with MEK in the presence of RKIP. As a result, downstream mitogen-activated protein kinase (MAPK) signaling is interrupted and diminished. As stated earlier, RKIP can bind to Raf-1 or MEK, yet not at the same time, and binding to either one is enough to cause downstream inhibition [Yeung et al., 2000]. In addition, it was postulated that RKIP may be involved in growth, transformation, and differentiation [Yeung et al., 1999] as these pathways are often deregulated in cancer.

RKIP interacts with small GTP-binding proteins, yet not GTP itself [Bucquoy et al., 1994] and can be purified along with $\mu$ opioid receptors via morphine affinity chromatography using tissue derived from rat brain [Grandy et al., 1990]. Grandy et al. [1990] speculated that RKIP was a membrane-associated protein, which may alter opioid binding via an enzymatic- or structural-induced reaction. Using hydrophobic cluster analysis and molecular modeling, Schoentgen et al. [1992] showed that the bovine RKIP may possess a potential nucleotide binding site and suggested that it belongs to the kinase family and promote the transfer of hydrophobic ligands to the plasma membrane. Co-expression of human RKIP with human opioid or somatastatin receptors (Gprotein-coupled receptors) in Xenopus laevis oocytes provided in vivo evidence that RKIP could modulate G-protein-coupled signaling [Kroslak et al., 2001]. 


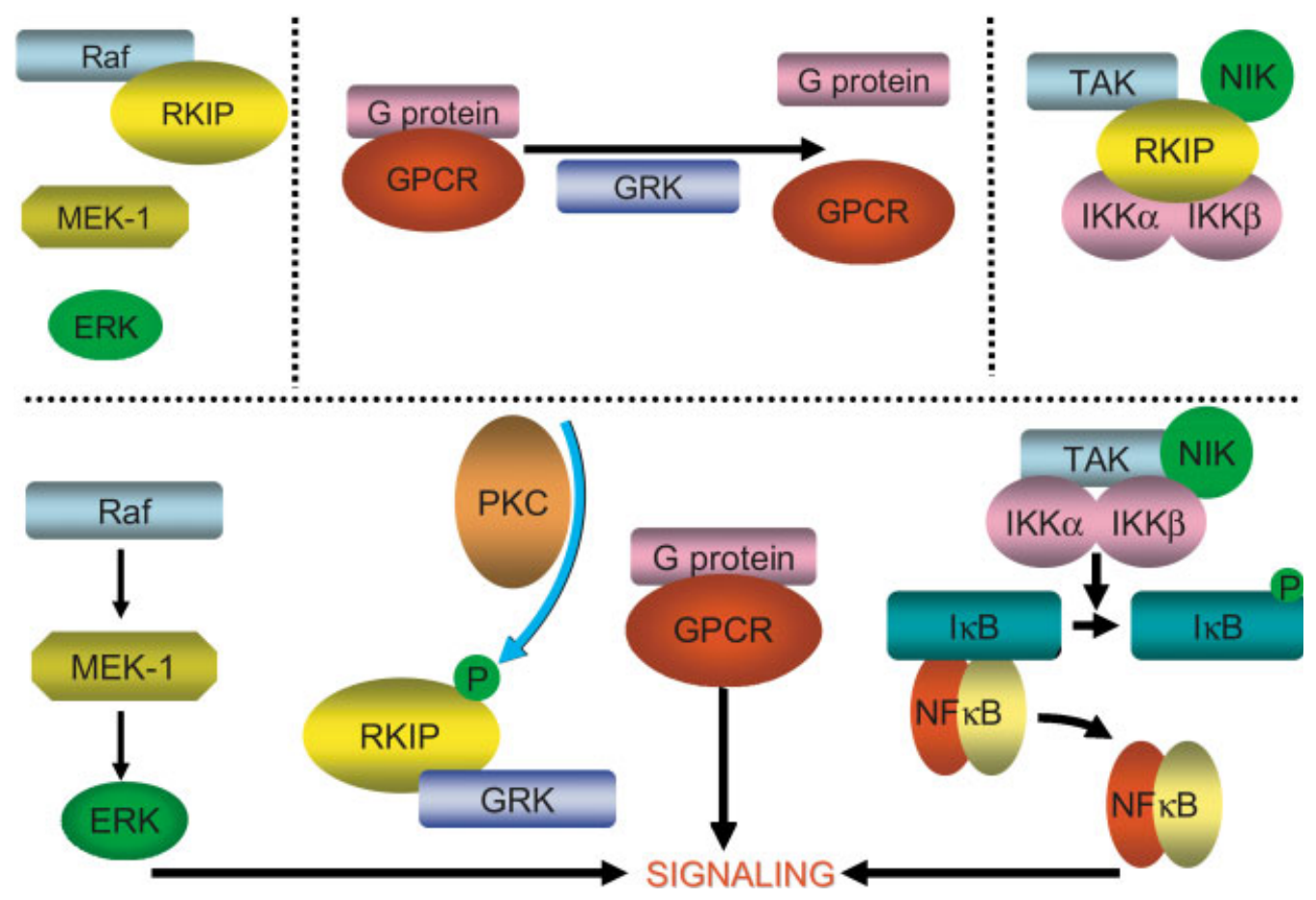

Fig. 2. Role of RKIP in intracellular signaling. Upper panels: In the inactive state, RKIP is unphosphorylated and binds to activated Raf, inhibiting its ability to activate MEK. Additionally, RKIP binds to several proteins that induce NF- $\kappa B$ activity including transforming growth factor $\beta$-activated kinase-1

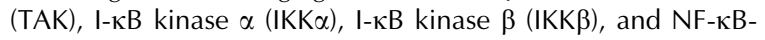
inducing kinase (NIK). Also, G-protein-coupled receptor kinase2 (GRK-2) binds to G-protein-coupled receptor (GPCR) resulting in inhibition of its activity. Lower panel: Activation of protein kinase C (PKC) results in phosphorylation of RKIP. The

phosphorylated RKIP releases Raf, which can then phosphorylate MEK, which in turns phosphorylates ERK. The phosphorylated RKIP can then bind to GRK-2, causing it to release, which allows GPCR to phosphorylate its downstream targets, including Raf. RKIP release from TAK, IKK $\alpha$, IKK $\beta$, and NIK results in phosphorylation and degradation of $\mathrm{I}-\mathrm{KB}$, which culiminates in release of $\mathrm{NF}-\kappa \mathrm{B}$ that translocates to the nucleus and binds on to target gene promoters. [Color figure can be viewed in the online issue, which is available at www.interscience. wiley.com.]

Protein kinase C (PKC), which phosphorylates target proteins that control growth, differentiation, and transcription, can inactivate RKIP through phosphorylation of RKIP on serine 153 and alleviate its inhibition of Raf-1 [Corbit et al., 2003]. PKC is normally recruited to the plasma membrane and activated by diacylglycerol. Its location near the plasma membrane may place it in close proximity to RKIP, which also binds to phospholipids [Bazzi et al., 1992]. As a result, PKC along with RKIP, function as unique selective regulators of the Raf-1/MEK/ERK growth factor signaling cascade. When RKIP is phosphorylated, it releases from Raf-1 and can bind onto G-protein-coupled receptor kinase-2 (GRK-2) preventing GRK-2's ability to inhibit G-protein-coupled receptor activity [Lorenz et al., 2003].

In summary, RKIP impacts multiple signaling pathways and RKIP activity itself is regulated by PKC. Due to its involvement in several signaling pathways, RKIP modulates cellular

functions that are dependent or altered by these signaling pathways.

\section{RKIP AS A SUPPRESSOR OF METASTASIS}

Metastasis, defined as the formation of progressively growing secondary tumor foci at sites discontinuous from the primary lesion [Yoshida et al., 2000], is a multi-step metastatic process. Initially, a metastatic cancer cell escapes from the primary tumor, enters the circulation, invades a distant tissue site and grows into a macroscopic tumor at the target site. Since many steps are required for metastasis to occur, it may be possible to block metastasis by inhibiting a single protein that is required for the completion of any one of these steps [Welch and Rinker-Schaeffer, 1999]. This hypothesis has given rise to the concept of metastasis suppressor genes (MSG). In brief, MSGs are defined as genes that inhibit the metastatic process, but not primary tumorigenesis. Several 


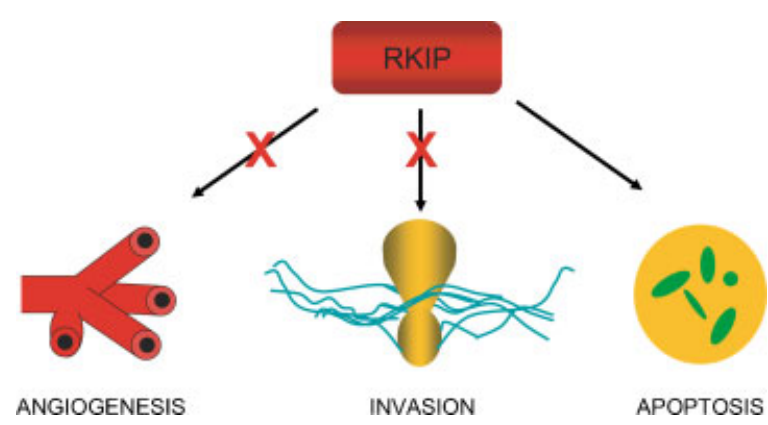

Fig. 3. Potential role of RKIP in metastasis. RKIP may modulate a variety of cellular functions that can impact development of successful metastases. For example, RKIP may inhibit angiogenesis and cell invasiveness and promote apoptosis. Thus, decreased RKIP expression promotes angiogenesis, cell invasion and confers resistance to apoptosis. [Color figure can be viewed in the online issue, which is available at www.interscience. wiley.com.]

studies that have demonstrated that loss of function of specific genes is an important event in the progression to malignancy support the concept of MSGs [Steeg et al., 1988; Dong et al., 1996; Yang et al., 1997; Yoshida et al., 2000]. Due to their ability to regulate the metastatic process, MSGs are potential diagnostic and therapeutic targets. Accordingly, identification of MSGs may lead to advances in prostate cancer therapy.

RKIP has been identified to have the properties of a prostate cancer MSG through inhibiting several potential pro-metastatic functions (Fig. 3). The initial clue that RKIP plays a role as a prostate cancer MSG was that RKIP mRNA expression was decreased in a metastatic prostate cancer cell line compared to its nonmetastatic parental cell line [Fu et al., 2002]. This relationship was confirmed at the protein level using immunohistochemistry to compare RKIP expression in non-neoplastic prostate tissue, primary prostate cancer, and prostate cancer metastases [Fu et al., 2003]. Specifically, RKIP expression level was highest for benign tissue, lower for cancerous tissue (declining with increasing Gleason score), and not detectable in metastases (of several different sites). These results provided strong evidence that loss of RKIP is associated with the development of prostate cancer metastases.

To examine the function of RKIP during prostate cancer progression, RKIP expression was modulated in prostate cancer cells to determine the effect of different RKIP levels on the prostate cancer cells metastatic ability.
Modulating RKIP expression had no effect on the ability of the cells to grow in vitro or on their ability to form colonies in soft agar. These results suggest that RKIP has no effect on these two primary tumorigenic properties of human prostate cancer cells. However, increasing RKIP expression in metastatic cancer cells decreased in vitro invasive ability [Fu et al., 2003]. Conversely, decreasing RKIP expression, using antisense, in non-metastatic prostate cancer cells increased their in vitro invasive ability. These results suggest that RKIP expression is inversely associated with the invasiveness of prostate cancer cells in vitro.

When the metastatic tumor cells that had RKIP expression restored were injected orthopically, the mice developed $70 \%$ less metastases (to lung) then mice that received the metastatic cells transfected with empty vector. Furthermore, in the mice that had received cells expressing restored RKIP and that developed metastases, the number of metastases was far fewer than in the mice that had received the cells expressing low levels of RKIP. Additionally, there was less vascular formation and less vascular invasion in the primary tumors derived from the mice that received the cells engineered to express RKIP. Taken together, these results suggest that RKIP functions as a suppressor of metastasis through decreasing angiogenesis and vascular invasion.

In addition to anti-metastatic properties, RKIP has pro-apoptotic properties in tumor cells. Exposure of breast and prostate cancer cells to chemotherapeutic agents induces RKIP expression and apoptosis [Chatterjee et al., 2004]. Small interfering RNA (siRNA) that targets and reduces RKIP expression diminishes chemotherapeutic-induced apoptosis. Additionally, breast and prostate cancer cells that have low levels of RKIP expression are resistant to chemotherapeutic-induced apoptosis [Chatterjee et al., 2004]. Restoration of RKIP levels sensitizes the cells to apoptosis. Taken together, these results suggest that loss of RKIP, as occurs in prostate cancer, may confer chemotherapeutic resistance on cancer cells and overall enhance tumor progression.

\section{CONCLUSIONS}

Prior to being named RKIP, this protein had been recognized as PEBP for many years. PEBP had contributed to many different physiologic 
activities including reproduction and neurophysiology. Recent research activity has identified that RKIP regulates an important signaling cascade, i.e., the Raf-MEK-ERK kinase cascade. In addition to this role, RKIP also modulates G-protein and NF- $\mathrm{BB}$ signaling. RKIP has been shown to contribute to several anti-cancer activities including induction of apoptosis and inhibition of metastasis. As prostate cancer progresses, it loses RKIP expression, which in turn, promotes metastasis and inhibition of apoptosis. These observations suggest that restoring RKIP expression or inhibiting effectors downstream of Raf that are normally blocked by RKIP will have potent anticancer effects.

\section{REFERENCES}

Banfield MJ, Barker JJ, Perry AC, Brady RL. 1998. Function from structure? The crystal structure of human phosphatidylethanolamine-binding protein suggests a role in membrane signal transduction. Structure 6:1245-1254.

Bazzi MD, Youakim MA, Nelsestuen GL. 1992. Importance of phosphatidylethanolamine for association of protein kinase $\mathrm{C}$ and other cytoplasmic proteins with membranes. Biochemistry 31:1125-1134.

Bucquoy S, Jolles P, Schoentgen F. 1994. Relationships between molecular interactions (nucleotides, lipids, and proteins) and structural features of the bovine brain 21-kDa protein. Eur J Biochem 225:1203-1210.

Chatterjee D, Bai Y, Wang Z, Beach S, Mott S, Roy R, Braastad C, Sun Y, Mukhopadhyay A, Aggarwal BB, Darnowski J, Pantazis P, Wyche J, Fu Z, Kitagwa Y, Keller ET, Sedivy JM, Yeung KC. 2004. RKIP sensitizes prostate and breast cancer cells to drug-induced apoptosis. J Biol Chem 279:17515-17523.

Corbit KC, Trakul N, Eves EM, Diaz B, Marshall M, Rosner MR. 2003. Activation of Raf-1 signaling by protein kinase $\mathrm{C}$ through a mechanism involving Raf kinase inhibitory protein. J Biol Chem 278:13061-13068.

Dong JT, Suzuki H, Pin SS, Bova GS, Schalken JA, Isaacs WB, Barrett JC, Isaacs JT. 1996. Down-regulation of the KAI1 metastasis suppressor gene during the progression of human prostatic cancer infrequently involves gene mutation or allelic loss. Cancer Res 56:4387-4390.

Frayne J, McMillen A, Love S, Hall L. 1998. Expression of phosphatidylethanolamine-binding protein in the male reproductive tract: Immunolocalisation and expression in prepubertal and adult rat testes and epididymides. Mol Reprod Dev 49:454-460.

Frayne J, Ingram C, Love S, Hall L. 1999. Localisation of phosphatidylethanolamine-binding protein in the brain and other tissues of the rat. Cell Tissue Res 298:415-423.

Fu Z, Dozmorov I, Keller E. 2002. Osteoblasts produce soluble factors that induce a gene expression pattern in non-metastatic prostate cancer cells, similar to that found in bone metastatic prostate cancer cells. Prostate $51: 10-20$.
Fu Z, Smith PC, Zhang L, Rubin MA, Dunn RL, Yao Z, Keller ET. 2003. Effects of raf kinase inhibitor protein expression on suppression of prostate cancer metastasis. J Natl Cancer Inst 95:878-889.

Grandy DK, Hanneman E, Bunzow J, Shih M, Machida CA, Bidlack JM, Civelli O. 1990. Purification, cloning, and tissue distribution of a $23-\mathrm{kDa}$ rat protein isolated by morphine affinity chromatography. Mol Endocrinol 4:1370-1376.

Jones R, Hall L. 1991. A $23 \mathrm{kDa}$ protein from rat sperm plasma membranes shows sequence similarity and phospholipid binding properties to a bovine brain cytosolic protein. Biochim Biophys Acta 1080:78-82.

Katada E, Mitake S, Matsukawa N, Otsuka Y, Tsugu Y, Fujimori O, Ojika K. 1996. Distribution of hippocampal cholinergic neurostimulating peptide (HCNP)-like immunoreactivity in organs and tissues of young Wistar rats. Histochem Cell Biol 105:43-51.

Katada E, Ojika K, Mitake S, Ueda R. 2000. Neuronal distribution and subcellular localization of HCNP-like immunoreactivity in rat small intestine. J Neurocytol 29:199-207.

Kroslak T, Koch T, Kahl E, Hollt V. 2001. Human phosphatidylethanolamine-binding protein facilitates heterotrimeric G protein-dependent signaling. J Biol Chem 276:39772-39778.

Lorenz K, Lohse MJ, Quitterer U. 2003. Protein kinase C switches the Raf kinase inhibitor from Raf-1 to GRK-2. Nature 426:574-579.

Maki M, Matsukawa N, Yuasa H, Otsuka Y, Yamamoto T, Akatsu H, Okamoto T, Ueda R, Ojika K. 2002. Decreased expression of hippocampal cholinergic neurostimulating peptide precursor protein mRNA in the hippocampus in Alzheimer disease. J Neuropathol Exp Neurol 61:176185.

Mitake S, Ojika K, Katada E, Otsuka Y, Matsukawa N, Fujimori O. 1995. Accumulation of hippocampal cholinergic neurostimulating peptide (HCNP)-related components in Hirano bodies. Neuropathol Appl Neurobiol 21: $35-40$.

Mitake S, Katada E, Otsuka Y, Matsukawa N, Iwase T, Tsugu T, Fujimori O, Ojika K. 1996. Possible implication of hippocampal cholinergic neurostimulating peptide (HCNP)-related components in Hirano body formation. Neuropathol Appl Neurobiol 22:440-445.

Moore C, Perry AC, Love S, Hall L. 1996. Sequence analysis and immunolocalisation of phosphatidylethanolamine binding protein (PBP) in human brain tissue. Brain Res Mol Brain Res 37:74-78.

Ojika K, Katada E, Tohdoh N, Mitake S, Otsuka Y, Matsukawa N, Tsugu Y. 1995. Demonstration of deacetylated hippocampal cholinergic neurostimulating peptide and its precursor protein in rat tissues. Brain Res 701:19-27.

Perry AC, Hall L, Bell AE, Jones R. 1994. Sequence analysis of a mammalian phospholipid-binding protein from testis and epididymis and its distribution between spermatozoa and extracellular secretions. Biochem J 301(Pt 1):235-242.

Saunders PT, McKinnell C, Millar MR, Gaughan J, Turner KJ, Jegou B, Syed V, Sharpe RM. 1995. Phosphatidylethanolamine binding protein is an abundant secretory product of haploid testicular germ cells in the rat. Mol Cell Endocrinol 107:221-230. 
Schoentgen F, Jolles P. 1995. From structure to function: Possible biological roles of a new widespread protein family binding hydrophobic ligands and displaying a nucleotide binding site. FEBS Lett 369:22-26.

Schoentgen F, Seddiqi N, Bucquoy S, Jolles P, LemesleVarloot L, Provost K, Mornon JP. 1992. Main structural and functional features of the basic cytosolic bovine 21 $\mathrm{kDa}$ protein delineated through hydrophobic cluster analysis and molecular modelling. Protein Eng 5:295303.

Simister PC, Banfield MJ, Brady RL. 2002. The crystal structure of PEBP-2, a homologue of the PEBP/RKIP family. Acta Crystallogr D Biol Crystallogr 58:1077-1080.

Steeg PS, Bevilacqua G, Kopper L, Thorgeirsson UP, Talmadge JE, Liotta LA, Sobel ME. 1988. Evidence for a novel gene associated with low tumor metastatic potential. J Natl Cancer Inst 80:200-204.

Taiji M, Tohdoh N, Ojika K. 1996. Neuronal expression of hippocampal cholinergic neurostimulating peptide (HCNP)-precursor mRNA in rat brain. J Neurosci Res 45:202-215.

Tohdoh N, Tojo S, Kimura M, Ishii T, Ojika K. 1997. Mechanism of expression of the rat HCNP precursor protein gene. Brain Res Mol Brain Res 45:24-32.

Tsugu Y, Ojika K, Matsukawa N, Iwase T, Otsuka Y, Katada E, Mitake S. 1998. High levels of hippocampal cholinergic neurostimulating peptide (HCNP) in the CSF of some patients with Alzheimer's disease. Eur J Neurol 5:561-569.

Vallee BS, Tauc P, Brochon JC, Maget-Dana R, Lelievre D, Metz-Boutigue MH, Bureaud N, Schoentgen F. 2001. Behaviour of bovine phosphatidylethanolamine-binding protein with model membranes. Evidence of affinity for negatively charged membranes. Eur J Biochem 268: 5831-5841.

Welch DR, Rinker-Schaeffer CW. 1999. What defines a useful marker of metastasis in human cancer? J Natl Cancer Inst 91:1351-1353.

Yang X, Welch DR, Phillips KK, Weissman BE, Wei LL. 1997. KAI1, a putative marker for metastatic potential in human breast cancer. Cancer Lett 119:149-155.

Yeung K, Seitz T, Li S, Janosch P, McFerran B, Kaiser C, Fee F, Katsanakis KD, Rose DW, Mischak H, Sedivy JM, Kolch W. 1999. Suppression of Raf-1 kinase activity and MAP kinase signalling by RKIP. Nature 401:173-177.

Yeung K, Janosch P, McFerran B, Rose DW, Mischak H, Sedivy JM, Kolch W. 2000. Mechanism of suppression of the Raf/MEK/extracellular signal-regulated kinase pathway by the raf kinase inhibitor protein. Mol Cell Biol 20:3079-3085.

Yoshida BA, Sokoloff MM, Welch DR, Rinker-Schaeffer CW. 2000. Metastasis-suppressor genes: A review and perspective on an emerging field. J Natl Cancer Inst 92:1717-1730. 